\title{
ГНОСТИЧЕСКИЕ ОСНОВАНИЯ ПРОЦЕССА ЭКОНОМИЧЕСКОЙ ГЛОБАЛИЗАЦИИ
}

\author{
Никулин Н. Н.
}

В статье автор обосновывает положение, что современный процесс глобализации в целлом и экономической глобализации в частности базируется на гностическом мировоззрении, суть которого заключается в стремлении решить проблему Спасения человека посредством Знания. При этом под Спасением понимается достижение бессмертия человека. В этом случае единственным средством решения данной задачи является научно-технический прогресс. Капиталистическая система производственных отношений направлена на непрерывное развитие производительных сил на базе рыночных отношений и конкуренции. Формирование условий для более быстрого роста производительных сил требует наиболее эффективного использования ресурсов человечества для достижения поставленной цели. Это предполагает свободное применение капитала вне зависимости от национальногосударственных и иных ограничений. Поэтому все ограничения применения капитала должны быть устранены. В этом суть экономической глобализаијии, которая в то же время является лишь условием реализации гностического взгляда на решение более сущностной проблемы.

Автор исходит из того положения, что путь Прогресса сосуществует с путем Веры на протяжении всего периода христианства. При этом начиная с эпохи Возрождения и в последующем эпохи Просвещения путь Прогресса постепенно усиливает свое влияние на общественное сознание человечества независимо от национально-государственных, религиозных, культурных и других взглядов. Данный дискурс становится все более принимаемым человечеством. Противопоставить ему что-то, кроме пути Веры, весьма сложно.

Ключевые слова: христианство, гностицизм, глобализачия, экономическая глобализация, прогресс, капитализм, коммунизм, модерн, постмодернизм.

In the article the author justifies the proposition that the basis of the modern process of globalization in general and economic globalization, in particular, is the Gnostic worldview, the essence of which lies in the desire to solve the problem of human salvation through Knowledge. In this case, salvation is understood as the attainment of the immortality of man. In this case, the only means of solving this problem is scientific and technological progress. The capitalist system of production relations is aimed at the continuous development of productive forces on the basis of market relations and competition. The formation of conditions for a more rapid growth of the productive forces requires the most effective use of the resources of mankind in order to achieve this goal. This implies the free use of capital, regardless of national-state and other restrictions. Therefore, all restrictions on the use of capital must be eliminated. This is the essence of economic globalization, which at the same time is only a condition for the realization of the Gnostic view of the solution of a more essential problem.

* Никулин Николай Николаевич - д. э. н., профессор НИТУ МИСиС. E-mail: nnnikulin@yandex.ru. 
The author proceeds from the premise that the path of Progress coexists with the path of the Faith throughout the entire period of Christianity. At the same time, starting with the Renaissance and later the Enlightenment, the Progress path gradually strengthens its influence on the public consciousness of mankind, regardless of national-state, religious, cultural and other views. This discourse is becoming increasingly accepted by mankind. Opposing him with something other than the path of the Faith is very difficult.

Keywords: Christianity, Gnosticism, globalization, economic globalization, progress, capitalism, communism, modernity, postmodernism.

Европа становится свободною... великое и славное освобождение достигнуто международною организацией соединенных сил всего европейского населения... старый, традиционный строй отдельных наций повсюду теряет значение, и почти везде исчезают последние остатки старых монархических учреждений. Европа в XXI веке представляет союз более или менее демократических государств - европейские соединенные штаты. ...А предметы внутреннего сознания - вопросы о жизни и смерти, об окончательной судьбе мира и человека... остаются по-прежнему без разрешения [Соловьев 1988: 739].

Анализируя сущность процесса глобализации современного мира, следует выявить глубинные факторы, которые лежат в его основе и одновременно являются базой для формирования противоречий, характеризующих этот процесс во всех областях общественной жизни, в том числе и экономической. По нашему мнению, хотя большинство людей чаще всего в своих действиях руководствуется краткосрочными материальными интересами, человек все равно задумывается над «вечными вопросами» бытия. И в глубинной основе, например, движения антиглобалистов лежит не только борьба за более справедливое распределение мирового дохода между государствами и народами. И исламский фундаментализм это не только реакция на более низкий уровень жизни в государствах, где большинство людей придерживается религии ислама.

Социальные противоречия, которые обострились в настоящее время, имеют давнюю историю. И связано это, по нашему мнению, с неоднозначностью ответа на вопросы, которые ставятся человеком в такой области познания, как сотериология (учение о Спасении человека).

Формируя отношение к экономической глобализации, необходимо руководствоваться ответом и на данную проблему. Поскольку социальные процессы в целом и экономические в частности субъектны, то от ответа на них зависит отношение человека и к более частным проблемам, например, к процессу глобализации экономики.

Капитализм - это не только способ производства материальных благ, но и форма организации общественной жизни на базе определенных ценностей, определенного взгляда на решение «вечного вопроса» о Спасении человека. В данном случае эта проблема решается, если следовать по пути Прогресса. И все, что стоит на данном пути, должно быть устранено. Именно поэтому экономическая глобализация, устраняющая национально-государственные ограничения в целях более эффективного использования ресурсов человечества, способствует решению вопроса о Спасении. 
Современная экономическая глобализация - это процесс формирования условий для свободного доступа мирового капитала к мировым ресурсам. Он выражается в нарастании открытости национальных экономик, формировании единых норм и правил функционирования капитала во всем мире.

На наш взгляд, в основе процесса глобализации в целом и экономической глобализации в частности лежат идеи, заложенные в общественное сознание в эпоху Возрождения такими мыслителями, как Паоло Сарпи (Paolo Sarpi, 15521623) и Фрэнсис Бэкон (Francis Bacon, 1561-1626), которые были развиты Рене Декартом (René Descartes, 1596-1650) Джамбаттистой Вико (Giambattista Vico, 1668-1744), Дэвидом Юмом (David Hume, 1711-1776), Иеремией Бентамом (Jeremy Bentham, 1748-1832). Они стали тем основанием, на котором развивались идеи прогресса, утилитаризма, позитивизма. «Scientia potentia est» - «Знание сила»: в этом афоризме Ф. Бэкона заключается весь смысл данных идей.

В то же время, по нашему мнению, они, в свою очередь, были реализацией древнего гностического подхода к решению главной задачи, которая стоит перед человеком в рамках сотериологии, а именно - проблемы Спасения.

Отличие Новой эпохи от Античности в этом и состоит. Античные герои только восставали против богов, изредка «вырывая» у них некоторые знания (Прометей), облегчающие условия существования. Но при этом не ставилась проблема Спасения человека. Гностицизм и христианство давали человеку такое Спасение, предложив два пути: Гносис, с одной стороны, и Веру в искупительную жертву Христа - с другой.

Решение данной задачи с помощью Гносиса посредством Прогресса, с одной стороны, или же с помощью Веры - с другой, различает в своей онтологической основе все направления общественной мысли.

Так, если брать историю «христианского мира», то здесь на протяжении всего этого периода можно наблюдать борьбу гностицизма и христианства. И если христианство принимает путь Спасения исключительно через жертвенное искупление Христа, то гностический путь Спасения возможен через Гносис - Знание. При этом, на наш взгляд, под Спасением следует понимать достижение людьми индивидуального бессмертия. В этой связи задача Прогресса - вырастить «древо жизни» и таким образом решить задачу Спасения человека.

Зародившись еще в первом веке, гностические идеи питали многочисленные учения прошлого, и они вновь возрождаются в современных оккультно-мистических движениях и учениях. Ученик Мартина Хайдеггера (Martin Heidegger, 1889-1976) американский философ Ганс Йонас (Hans Jonas, 1903-1993) в своей известной работе вводит даже специальное понятие «гностической цивилизации» [Йонас 1998].

Общей идеей всех гностических учений является получение знания, но не просто теоретического знания, а знания как энергии и силы, несущей человеку спасение. Идея этого знания во всех случаях была единой - сотериологической («спасительной»). И хотя, согласно В. С. Соловьеву, «гностицизм есть кажущееся спасение» [Соловьев 1894: 951], в данном случае важно, что гностицизм претендует на то, чтобы указать такой путь.

Следует особо отметить в связи с темой статьи, что идеи гностицизма широко используются в организации общественного устройства. Так, в современной мировой гностической традиции принято считать, что один из самых известных представителей гностицизма Ф. Бэкон - это «отец» современной западной цивилизации, которая продолжает жить «по Бэкону», используя те структуры, которые он создал и оставил миру в наследство. 
Учения, теории, взгляды гностицизма имеют возможность приспосабливаться к изменению внешних условий. Они, с одной стороны, учитывают результаты развития естественных и общественных наук, с другой - сами влияют на направление и эффективность их развития. Результатом такого взаимодействия стало постепенное формирование в эпоху Просвещения рационального взгляда на человеческую жизнь, на исторический процесс в целом. Идея исторического процесса в рамках сотериологии гностицизма стала выражаться в идее Прогресса. Сделавшись основой большинства философско-политических течений Нового времени, она давно уже стала своеобразной верой, определяющей мировоззренческие ориентиры современности. Как пишет С. Н. Булгаков, «теория прогресса для современного человечества есть нечто гораздо большее, нежели всякая рядовая научная теория, сколь бы важную роль эта последняя ни играла в науке. ...В теории прогресса позитивная наука хочет поглотить и метафизику и религиозную веру, точнее, она хочет быть триединством науки, метафизики и религиозного учения. Позитивная теория прогресса является своего рода эсхатологией» [Булгаков 1990: 269, 270].

Под «прогрессом» (от латинского слова «progressus», что означает «движение вперед, успех») принято подразумевать тип и направление развития, для которого характерен переход от низшего состояния к высшему. Основная задача, которую ставит теория прогресса, заключается в том, чтобы показать, что история имеет смысл и ее цель - «раскрытие плана истории, ее цели и форм движения». Как отмечал в этой связи В. С. Соловьев, «Бог не может быть только Богом геометрии и физики. Ему необходимо быть также Богом истории» [Соловьев 1913].

Рационалистское понимание исторического развития, возникшее в эпоху Просвещения, превратилось со временем в непререкаемую идеологическую установку. Термин «прогресс» становится синонимом понятию развития вообще. Регрессом, соответственно, начинает считаться все то, что препятствует данному движению или не приемлет его.

Идея непрерывного прогресса в конечном счете направлена на решение проблемы спасения человека, которое становится возможным в результате развития науки и техники. Идея Прогресса - это современная интерпретация гностической идеи, как и прежде, противостоящая христианской идее спасения.

Существенной чертой прогресса следует признать стремление к унификации и стандартизации фактически всех сфер человеческой жизнедеятельности. Оно распространяется как на внутреннюю сторону жизни Запада, так и на иные культурные пространства. Идеология прогресса стала действенным и эффективным духовным оружием Запада. Идея Прогресса, по нашему мнению, постепенно проникает во все страны. Как в своей обыденной жизни человек принимает эту идею, так и в вопросах сотериологии нарастает надежда на то, что наука откроет для человека возможность преодоления смерти в той или иной форме.

В то же время следует отметить, что и в современных условиях одновременно сохраняется иное, религиозное понимание сотериологии. Большое влияние на это оказывают, на наш взгляд, два момента. Первый - «научный» путь, он не распространяется в настоящее время на большую часть человечества. Значительный разрыв в экономическом развитии между государствами не позволяет большинству стран рассчитывать на решение проблемы спасения на пути Прогресса. Второй длительность ожидания и понимание того, что для настоящих поколений данный путь также недостижим. 
Конечно, кто-то в идею бессмертия не верит, а кто-то ее даже не приемлет ни в какой форме. Но все-таки, наверное, исходя из опыта исторического мышления с древних времен, данная идея присуща человеку. В этом отношении народы отличаются только пониманием пути, который приводит человека к Спасению. Исходя из такого понимания сотериологии, на наш взгляд, можно говорить об определенном единстве человеческого общества.

Характеризуя современность, А. И. Неклесса определяет ее как конец эпохи Большого Модерна, понимая под ним мир христианской универсальности: «Истоки почти двухтысячелетней цивилизации Большого Модерна (Modernus) коренятся в христианском сознании. Христиане еще на заре новой цивилизации называли себя moderni, отличая таким образом свою общность от людей предшествовавшего, ветхого мира - antiqui». При этом в основе социальной общности западного мира до некоторого времени были христианская идея спасения и определенное понимание формы земного мироустройства. В то же время середина II тысячелетия, по мнению А. И. Неклессы, - это время зарождения современного мира, то есть Мира Модерна (Modernity). «Яркая черта Мира Модерна, - отмечает ученый, - сосуществование в его пространстве двух исторических тенденций. Наряду с утверждением христианского мира, цивилизации универсалистской и прозелитической в качестве основного субъекта исторического действия, к древу истории во втором тысячелетии в какой-то момент прививается иной побег, произраставший из семян светского антропоцентризма и гностических ересей. Эта ветвь, разросшись и укрепившись, вызвала со временем мутацию могучего европейского организма, породив современный нам экономический универсум, североатлантический мир, Запад в его нынешнем статусе и захлестывающий ныне планету девятый вал глобализации» [Неклесса 2001a: 69]. При этом капитализм, по мнению А. И. Неклессы, начавший ускоренными темпами развиваться с этого времени, не столько форма эффективной хозяйственной деятельности, естественным образом возникающая на базе рыночной экономики, сколько социальная стратегия, целостная идеология и схема специфического мироустройства [Там же: 132]. Глобальный капитализм, замечает в этой же связи французский социолог Жак Бодо (Jacque Baudot), «представляет собой не только экономическую систему с ее достоинствами и недостатками, но также и идеологию, предлагающую всеобъемлющую точку зрения на личное счастье и общественную гармонию. По мнению некоторых из его наиболее преданных лидеров и адептов, глобальный капитализм обладает всеми атрибутами фундаменталистской религии» [Бодо 1998: 95, 97].

В эпоху Возрождения общество начинает возвращаться к культурным ценностям Античности. Возрождение пробудило интерес к реальному миру, без которого не было бы и развития науки и техники. Именно в этот период начинает изменяться понимание сущности человека и его ценностей. «Человек - это звучит гордо!» - так мог сказать только гностик! В христианстве гордыня является одним из самых тяжких грехов человека перед Богом.

Именно в данный период начинается определенный отход европейского общества от христианского взгляда на мир. Возобладал гностический подход к решению всех проблем, стоящих перед человеком. Так, французский католический философ Жозеф де Местр (Joseph de Maistre, 1753-1821), описывая Французскую революцию, отмечал: «Настоящее поколение является свидетелем одного из самых великих спектаклей, когда-либо занимавших человеческий глаз: это борьба не на жизнь, а на смерть христианства и философизма. Ристалище открыто, два врага схватились, и Вселенная смотрит» [Местр 1997: 69, 76]. 
В этот же период в Европе формируется «фаустовский» тип личности. В легенде о докторе Фаусте говорится, что он «захотел постигнуть все глубины неба и земли», «исследовать первопричины всех вещей», надеялся, что «сумеет, наконец, увидеть рай» [Легенда... 1958: 48, 97].

Можно заметить, что в деятельности и суждениях Фауста отчетливо проявились основные черты зародившейся в эпоху Возрождения европейской, западной культуры: приверженность рационализму и научному знанию (сциентизм), стремление человека постоянно приумножать материальное богатство, индивидуализм и готовность человека к постоянным переменам в производстве и потреблении, семейных отношениях, моральных ценностях и т. д. Фауст с неизбежностью должен был стать экономическим человеком, творцом капиталистических отношений. Как пишет В. А. Красильщиков, именно «в эпоху Возрождения истории отдельных стран и народов слились в общий поток всемирной истории, a XV столетие - тот исторический рубеж, начиная с которого складывается современная мировая система хозяйства. Тогда Запад, по существу, навязал свою модель развития почти всему остальному миру, и в сознании европейцев зародилась вера в универсальность своего общественного устройства и своих ценностей, которая сохранилась и сегодня» [Красильщиков 1994: 86].

Таким образом, именно в идеях Возрождения и Просвещения многие исследователи видят основу для становления рационализма, утилитаризма и капитализма, что дало толчок развитию производительных сил в западном мире.

Однако, по нашему мнению, на основе такого подхода можно разделять на отдельные эпохи только реальную социально-экономическую историю человечества. В то же время духовная история в своей глубинной основе неделима. Конечно, конкретные формы реализации духовного начала человека в тех или иных мифах, религиях, учениях меняются, но все они выражают что-то общее: Рай, Золотой век, Спасение. И в этом плане христианство никогда не было единственным путем движения к такому состоянию. В любой момент истории рядом находились «миры-двойники». В Средние века началось ускоренное развитие одного из таких «миров» - мира Прогресса. Однако его основы были заложены эпохой гностицизма. Этот путь предполагал активное начало в человеке. Конечно, никто не сможет сегодня доказать, что этот путь единственно верный. Но человечество его в конце концов приняло, хотя, естественно, не сразу и не без жестокой порой борьбы и многочисленных жертв. Можно сказать, что «ветхому миру - antique» в Европе с самого начала противостояли два «мира»: христианский и гностический. В этом отношении можно говорить не только о христианском Большом Модерне, но и о гностическом Большом Модерне. Оба противостояли «античному миру». Оба провозглашали основной целью Спасение человека. Но пути спасения определяли по-разному: через Христа и через Гносис. В настоящее время оба пути открыты для человека и ему предоставляется возможность выбора, если, конечно, он стремится к Спасению и верит в него.

Поэтому нельзя согласиться с В. Максименко, когда он пишет, что «глобализм - это идеология подмены (предметного беспредметным), не позволяющая рассмотреть, что есть два новых времени - действительное и мнимое: Новое время христианского благовестия, содержащее обетование “новой твари”, и антихристианская фальсификация Нового времени в утопии “нового секулярного порядка” (“нового мирового порядка”) - novus ordo saeclorum» [Максименко 1999а].

На наш взгляд, эти два пути, по крайней мере в европейской культуре, слишком долго сосуществовали, чтобы один из них был легко преодолен. 
В этой связи, по нашему мнению, также нет оснований, как это делают многие исследователи, и выделять эпоху «постмодернизма», и тем более полагать, как А. И. Неклесса, что формируется какая-то новая цивилизация. «Ныне обезбоженный индивид, вооруженный многочисленными дарами ранее вкушенной свободы, - пишет он, - воплощает уже иные идеалы и творит иную историю, выходящую за границы устремлений прежней цивилизации, выстраивая многоярусный мир социального Постмодерна, в котором прежняя история теряет смысл. На месте устремленной в будущее стрелы времени западной цивилизации развертывается самодостаточное, все более проникающееся восточным духом "мира и безопасности" и тягой к статичности пространство новой, в сущности неведомой цивилизации мирового Севера» [Неклесса 2000].

На наш взгляд, так называемый «постмодернизм» на самом деле - это одна из современных форм гностического Большого Модерна, если, конечно, за ним видеть нечто большее, чем «голое отрицание» всего и вся, «Большой Пофигизм».

Известный исследователь постмодернизма Петер Козловски (Peter Koslowski, 1952-2012) отмечает: «Модерн - это вера в обоснованность притязаний естественных наук на тотальное просвещение. $<\ldots>$ Когда модерн разочаровывается в скорой осуществимости своих утопических ожиданий, он впадает в апокалипсическое отчаяние; когда же и здесь наступает разочарование - потому что апокалипсис не наступает, модерн оказывается обреченным на нигилизм <... Поздняя античность на разочарование в своих ожиданиях ответила гностицизмом. Сегодня мы можем наблюдать, как на смену гностицизму и религии приходит нигилизм $<. .>$ Постмодерн принимает на себя роль тормоза, отодвигающего наступление того, что собственно должно было наступить после крушения утопических историко-философских ожиданий современности: гибели. Предназначение человека разрушить самого себя. Но только прежде он должен стать достоин этого; пока же - еще нет. Эпоха постмодерна представляет собой время, которое остается людям, чтобы стать достойными гибели» [Козловски 1997: 34, 35, 47].

Однако заметим, что большинство людей предпочитает жизнь, человечество идет на многое, чтобы увеличить продолжительность жизни. По нашему мнению, так называемый постмодернизм - это еще одна «игра в бисер», еще один «закат Европы», поскольку он ничего не противопоставляет гностическому Модерну как мировоззрению, в основе которого лежит идея Спасения посредством Знания. «Постмодерн не выступает как антитеза модерна, их видимое различие скрывает единый глубинный вектор - движение к техногенному глобальному капитализму» [Мясникова 2001: 15].

Этому движению может противостоять только идея христианского Модерна. Поэтому, на наш взгляд, можно согласиться с В. И. Пантиным, который отмечает: «Основные политические институты, ценности и тенденции, возникшие в рамках Модерна, продолжают играть ключевую роль в развитии стран Запада, несмотря на все изменения, связанные с процессами информатизации, глобализации, утверждением постиндустриализма. Вступление стран Запада в стадию постиндустриального развития еще не выводит их за рамки Модерна, а лишь усиливает разрыв между ними и остальным миром» [Пантин 2001: 200]. Заметим, именно за рамки Большого Модерна.

Конечно, можно исходить и из пессимистическо-нигилистического взгляда на жизнь: идет себе и идет. Живут же животные, растут растения, сменяя друг друга. Так и люди. И не стоит искать какого-то смысла во всем этом. А разум человеку 
дан просто для поддержания жизни, как инстинкт животным и фотосинтез растениям. Жизнь для поддержания непрерывного жизненного процесса. Но тогда...

По нашему мнению, основной тенденцией развития человеческого общества в настоящее время становится нарастание однородности всех сторон общественной жизни на принципах гностического рационализма. И «плавильным котлом» в данном случае является уже весь земной шар. Еще А. Дж. Тойнби писал: «Будущий мир не будет ни западным, ни незападным, но унаследует все культуры, которые мы заварили все в одном тигле». При этом Западу «было предназначено $<\ldots>$ совершить что-то не просто для себя, но для всего человечества» - возвести «строительные леса, внутри которых все ранее разбросанные общества построили бы одно общее. Эти леса - наука и технология» [Тойнби 1996: 66]. Кроме того, по нашему мнению, к таким «строительным лесам» можно отнести и демократическую форму организации общества, и рыночную экономику.

Конечно, в рационалистическом подходе к проблемам сотериологии остается немало вопросов, которые на данном этапе развития человеческого общества остаются без ответа (главный, на наш взгляд: а для чего нужно бессмертие?). Может, это и так. Однако это столь же «абстрактное» возражение, как и подобные вопросы сторонников «рационализма» в адрес религиозного мировоззрения. В то же время реальные достижения в области генетики, медицины, нанотехнологий, информационных технологий вселяют в человека надежду, что задача спасения в форме достижения бессмертия может быть решена.

Таким образом, по нашему мнению, в современных условиях путь Прогресса становится принимаемым все большей частью людей в большинстве стран мира. Стремление жить «лучше и дольше» распространяется все шире, а развитие науки и техники все больше обеспечивает такую возможность. Именно этот путь, по нашему мнению, в конечном счете ведет к объединению человечества, в то время как путь Веры (путь Христа, Мохаммеда, Будды и т. д.) часто ведет к разъединению людей, к «борьбе с неверными», религиозным войнам.

В то же время, как уже не раз отмечалось, гностический путь рационализма в развитии человеческого общества принимается не всеми. Достижения на пути прогресса зачастую объявляются ложными, не ведущими человека к истинному спасению.

Непринятие рационализма в конечном счете приводит к непринятию Запада в целом как мира, как образа жизни, как системы ценностей. Согласно подобным представлениям западный тип цивилизованного человека должен быть искоренен.

Цивилизация - это процесс возобладания разума над инстинктом. Большинство современных террористов, независимо от вероисповедания, едины в том, против чего они борются, а не ради чего. «Цель новых социальных движений, отмечает в этой связи П. Козловски, - в первую очередь, не завоевание политикоэкономической власти, а охрана определенных форм и образа жизни» [Козловски 1997: 91].

Потому и жизнестойки такого рода уклады и группировки, что они базируются на очень прочном фундаменте: на Вере в иной, не рациональный путь Спасения. И только значительные успехи на пути Прогресса в решении этой задачи смогут уменьшить число их сторонников.

Таким образом, по нашему мнению, глобализм можно характеризовать как объединение человечества для решения задачи Спасения на гностическом пути. Глобализация в этом смысле является позитивным процессом с учетом принятия данной цели и способа ее достижения. Идея Прогресса, связанная с поисками пу- 
тей спасения на почве «гносиса», никогда полностью не уходила из человеческого мировоззрения и тем более останется в будущем, хотя такая точка зрения и разделяется не всеми. В то же время, скорее всего, прав немецкий политолог Клаус Зегберс (Klaus Segbers, 1954), полагающий, что «реально существующих и поддержанных весомыми социальными группами альтернативных макропроектов нет. В этом смысле история - не реальная, а история концептов - кажется, и вправду подошла к своему “концу”. Сейчас вестернизации и рыночному регулированию сопротивляются лишь остающиеся в глухой обороне неисправимые фундаменталисты» [Зегберс 1999].

Следует только сказать, что таких «концептов», на наш взгляд, всегда было два: гностический и религиозный. Все остальное - теории, концепции и т. п. было в рамках этих «концептов». На наш взгляд, в этой связи прав французский историк Франсуа Фюре (François Furet, 1927-1997), когда пишет: «Либерализм, коммунизм, фашизм, последовательно выходившие из чрева Революции, при всей ярости их столкновений в XX веке реальной альтернативы друг другу в себе не несли. Плоть от плоти эпохи модерна, они были одинаково одержимы революционной страстью, одинаково питали себя ненасыщающим духом Революции» [цит. по: Максименко 1999б].

То, что коммунизм и капитализм являются однокачественными явлениями человеческой истории с точки зрения высшей цели для человека, по нашему мнению, вытекает из их одинакового взгляда на иной, нерелигиозный путь спасения. Атеизм, будь то в форме прямого отрицания Бога или же в следовании гностическому мировоззрению, присущ обеим общественно-политическим системам. «Философы, - писал К. Маркс, - лишь различным образом объясняли мир, но дело заключается в том, чтобы изменить его» [Маркс 1955: 4]. Но изменить мир это значит придать ему иные, желательные нам черты в соответствии с нашим представлением о мире. И в данном случае человек становится творцом нового мира.

В то же время следует отметить, что человек может формировать представление о возможном «конце истории», о том, что под ним понимать и каким образом реализовать задачу спасения. Расхождения в ответах на эти вопросы и формируют основу для появления глобальных противоречий в человеческом обществе. На данном этапе своего развития человечество неоднородно во многих отношениях. Оно поделено на государства, нации, народы, социальные группы и т. д. И не все хотят и могут жить по единым правилам, которые навязывает глобализация. Отсюда возникает стремление к обособлению, конфликты на национальной и религиозной почве, попытки народов отстоять свои культуру, самобытность, образ жизни. Кроме того, человечество разделено на разные поколения. Естественно, согласовать интересы (экономические, политические, национальные, социальные, индивидуальные) на гностической идее Спасения в этих условиях очень сложно. Кроме того, как отмечалось выше, не все принимают Спасение через Прогресс за истинное Спасение, а кто-то никакого пути к Спасению не видит и тем более не хочет его. Такого рода конфликты носят в большей степени мировоззренческий, чем социально-экономический характер.

Кроме того, отмеченный выше факт невозможности решения задачи Спасения в ближайшем будущем в еще большей степени обостряет противоречивость всех вышеперечисленных интересов.

Поэтому, понимая глобализацию как процесс, направленный на обеспечение более благоприятных условий для гностического решения важнейшей задачи, 
стоящей перед человеком, необходимо одновременно учитывать геополитические и экономические интересы разных народов и государств. Почему это необходимо делать - обосновать очень сложно, особенно если исходить из высокой цели Спасения и длительного исторического периода времени. Можно, например, предположить, что у отдельных народов имеет место страх быть исключенными по каким-то причинам из процесса Спасения, или что кто-то полагает: путь Прогресса - это не путь Спасения. Все остальные аргументы против глобализации, на наш взгляд, являются частными, производными.

При определении стратегического курса развития государства следует ставить и «вечные вопросы». Конечно, их озвучивание в общественном масштабе не означает, что уже сегодня имеется их решение, но человеку часто необходимо просто знать, что такие вопросы стоят не только перед ним одним, а перед всем обществом, и руководители государства, формируя и реализуя ту или иную политику страны, учитывают их.

Подобный подход должен иметь место и при разработке стратегии в отношении как глобализации в целом, так и экономической глобализации в частности. Сегодня происходит определенное нивелирование в понимании «вечных вопросов» и ответов на них. Люди начинают одинаково смотреть на многие вещи. Доступность информации, культурное взаимопроникновение подготавливают условия для формирования единого мировоззренческого взгляда на проблемы как отдельного человека, так и человечества в целом.

Когда С. Н. Булгаков писал, что «позитивная теория прогресса является бездоказательной, иррациональной и потому ненаучной» [Булгаков 1990: 297], он исходил из того, что без Бога нельзя дать ответ на вопрос «что же представляет собою наш мир в целом?». Однако, по нашему мнению, религиозное миропонимание в этом отношении столь же иррационально и бездоказательно.

Наверное, строго говоря, вопросы бытия человека сложно поддаются рациональному анализу в системе причинно-следственных взаимосвязей. Глобализм, на наш взгляд, - это сближение понимания у разных народов в вопросах сотериологии. В этих условиях и принципы организации общественных отношений в различных государствах становятся схожими. Можно сказать, что глобализация это процесс распространения и принятия одинаковых взглядов на сущность человеческого существования мировым сообществом в целом на основе гностического пути Спасения. При этом, естественно, принимаются и общие правила поведения, которые разрабатываются в наиболее развитых в техническом, экономическом, научном плане государствах. Это объективно. Нельзя жить в мире и быть независимым от мира. Если, конечно, не стремиться к созданию автаркического общества на основе принятия иных принципов и ценностей, иного пути Спасения.

При этом главной задачей, на наш взгляд, становится создание условий для объединения ресурсов человечества для решения проблемы Спасения на пути прогресса. «Рационально править миром, - замечает Э. Кочетов, - вот гигантская задача современного человечества» [Кочетов 2001: 73].

Добавим, что «рационально» - это значит с точки зрения решения проблемы Спасения. Без ориентации на достижение этой цели управление с неизбежностью будет нерациональным.

В этой связи открытость национальных государств, отсутствие запретов и ограничений на рост взаимосвязей во всех областях общественных отношений становятся необходимой основой решения как индивидуальных, так и общечеловеческой задач. 
Эпоха Болышого Модерна не закончилась. При этом гностическая идея Спасения объединяет все новые и новые страны и народы. Ценности Прогресса, развитие науки и техники, рыночно-демократическая форма организации общества не означают понижения или даже отсутствия духовности в обществе, нравственных начал в отношениях между людьми. Как по отдельным деяниям Церквей нельзя судить об их неправедности в целом, так и по отдельным проявлениям капитализма нельзя делать вывод о его полной безнравственности.

Следует также отметить, что в настоящее время что-то противопоставить процессу и концепции глобализации, на наш взгляд, весьма сложно. Для этого необходим проект «универсализма», конкурирующий с западным проектом Прогресса. «В какой-то степени духовное всесилие современной "североатлантической” цивилизации, - пишет в этом отношении Б. В. Межуев, - порождено тем, что все “вызовы”, с которыми ей приходится иметь дело в настоящее время, окрашены в национал-изоляционистские или религиозно-фундаменталистские тона. Это всесилие обусловлено и отсутствием на поле "глобализма" у нее серьезных конкурентов» [Межуев 2001: 267].

Глобализация с начала 90-х гг. ХХ в. становится преобладающей теоретической концепцией, с одной стороны, и реальным общественным процессом с другой. И данный процесс, на наш взгляд, являясь объективным (в том смысле, что он предопределяется реальной динамикой производительных сил), неостановим и отвечает истинным интересам как отдельных людей, так и человечества в целом. Конечно, «путь Веры» для человечества также не закрыт, и нам не дано знать, какие открытия могут ждать человека на этом пути. Но на данном этапе развития общества «путь Прогресса» становится для все большего числа людей в реальности основным в решении задачи Спасения. Как отмечает А. И. Неклесса, «возводимые в недрах современного общества антропологическая и социальная конструкции имеют весьма глубокий, притом гораздо более древний, чем протестантизм, мировоззренческий фундамент, и фундамент этот принадлежит гностицизму. Соответственно, прорисовывающаяся в социальном пространстве постхристианская квазицивилизация, чей контур с каждым годом обретает все большую четкость... может быть - с соответствующими оговорками - определена по своим культурно-мировоззренческим основам как гностическая (выделено мной. - Н. Н.)» [Неклесса 2011б].

Однако, как мы стремились показать, по нашему мнению, то, что «прорисовывается», на самом деле существовало постоянно наряду с христианским мировоззрением. Это одна из «ветвей древа истории» эпохи Большого Модерна, сутью которого является поиск Пути Спасения для Человека. И на современной стадии исторического процесса «гностическая ветвь» начала развиваться более бурно. При этом считать ее «квазицивилизационной», по нашему мнению, неправомерно.

\section{Лuтература}

Бодо Ж. Глобальный капитализм: необходимость в обновлении универсалистской модели // Мировая экономика и международные отношения. 1998. № 12. С. 94-99.

Булгаков С. Н. Философия хозяйства. М. : Наука, 1990.

Зегберс К. Сшивая лоскутное одеяло // Pro et Contra. 1999. Т. 4, осень [Электронный ресурc]. URL: http://pubs.carnegie.ru/p\&c.

Йонас Г. Гностицизм (Гностическая религия). СПб. : Лань, 1998. 
Козловски П. Культура постмодерна: Общественно-культурные последствия технического развития. М. : Республика, 1997.

Кочетов Э. Осознание глобального мира // Мировая экономика и международные отношения. 2001. № 5. С. 71-76.

Красильщиков В. А. Превращения доктора Фауста. Книга, которая противопоказана экономистам и политикам. М. : Таурус, 1994.

Легенда о докторе Фаусте. (Серия «Литературные памятники».) М.; Л. : Изд-во АН СССР (Ленинградское отделение), 1958.

Максименко В. Происходит ли «глобализация»? // Pro et Contra. 1999а. Т. 4, осень [Электронный ресурс]. URL: http://pubs.carnegie.ru/p\&c/.

Максименко В. Три силы (заметки на полях «Прошлого одной иллюзии» Франсуа Фюре // Pro et Contra. 1999б. T. 4, лето [Электронный ресурc]. URL: http://knigi. dissers.ru/books/1/18339-1.php.

Маркс К. Тезисы о Фейербахе / К. Маркс, Ф. Энгельс // Соч. 2-е изд. Т. 3. М., 1955.

Межуев Б. В. Теория модернизации и геополитика: проблематичность концептуального соотнесения // Мегатренды мирового развития / под ред. М. В. Ильина, В. Л. Иноземцева. М. : Экономика, 2001. С. 261-267.

Местр Ж. де. Рассуждения о Франции. М. : РОССПЭН, 1997.

Мясникова Л. «Новая экономика» в пространстве постмодерна // Мировая экономика и международные отношения. 2001. № 12. С. 3-15.

Неклесса А. И. Конец эпохи Большого Модерна // Знамя. 2000. № 1 [Электронный pecypc]. URL: http://magazines.russ.ru/znamia/2000/1/nekles.html.

Неклесса А. И. Ordo Quardo: пришествие постсовременного мира // Мегатренды мирового развития / под ред. М. В. Ильина, В. Л. Иноземцева. М. : Экономика, $2001 \mathrm{a}$. C. $129-133$.

Неклесса А. И. Постсовременная цивилизация // Прикладные аспекты цивилизации. Материалы постоянно действующего семинара клуба ученых «Глобальный мир». Спецвыпуск. (Материалы научно-практического семинара «Прикладные аспекты глобализации». 20-21 сентября 2001 г.) М., 2001б. С. 24-28.

Пантин В. И. Гомогенизация как тенденция // Мегатренды мирового развития / под ред. М. В. Ильина, В. Л. Иноземцева. М. : Экономика, 2001. С. 199-201 [Электронный ресурc]. URL: http://www.gatchino.com/knogg/2001_015.htm.

Соловьев В. С. Гностицизм // Энциклопедический словарь. Т. VIII-А. СПб. : Ф. А. Брокгауз и И. А. Ефрон, 1894.

Соловьев В. С. Понятие о Боге. (В защиту философии Спинозы.) / В. С. Соловьев // Собр. соч. Т. 9. СПб., 1913 [Электронный ресурс]. URL: http://www.odinblago.ru/solo viev_9/1.

Соловьев Вл. Три разговора о войне, прогрессе и конце всемирной истории, со включением краткой повести об Антихристе и с приложениями / Вл. Соловьев // Соч.: в 2 т. Т. 2. М. : Мысль, 1988.

Тойнби А. Дж. Цивилизация перед судом истории. М. : Прогресс, 1996. 